\title{
THE EFFECT OF INTERFACE ON USER TRUST; USER BEHAVIOR IN E-COMMERCE PRODUCTS
}

\author{
N. Yashmi ${ }^{1, \otimes}$, E. Momenzadeh ${ }^{1}$, S. Taghipour Anvari ${ }^{2}$, P. Adibzade $^{3}$, \\ M. Moosavipoor ${ }^{4}$, M. Sarikhani ${ }^{1}$ and K. Feridouni ${ }^{1}$ \\ ${ }^{1}$ Bahar E-Commerce Services, Iran, ${ }^{2}$ University of Tehran, Iran, ${ }^{3}$ Tehran University of Art, Iran, ${ }^{4}$ infinityDesign, Iran \\ $\bigotimes$ yashmi@bahar.finance
}

\begin{abstract}
In this analytical research, the dependency of trust on the user interface in e-commerce has been reviewed. The approach of this case study on payment gateways (PGs) was a combination of the cross-sectional analysis and empirical study. First, the situation of a PG was evaluated in the marketing campaign. Then, the UI of 8 famous PGs was redesigned and 160 volunteers ranked the credibility of each page. Finally, the highest-ranked page was implemented, and the campaign was repeated. Results showed the users who trusted increased from $23.4 \%$ to $54.5 \%$ due to a new UI design.
\end{abstract}

Keywords: human behaviour, interface management, human-centred design, online payment, e-commerce

\section{Introduction}

Trust building has always been one of the most significant issues for businesses, especially ecommerce ones (Corbitt et al., 2003). For such business, web-based payment is the most-used method by which customers are directed to a payment gateway to complete their purchases by entering their credit cards, debit cards, or other types of banking cards number and additional information. Therefore it seems it is even harder to trust when it comes to online payment, in comparison with offline payment, as criminals or hackers may get that information (El-Din et al., 2014). There is no need to mention if an online business is not able to gain the customers' trust, it would not be able to survive in the market because trust has the most effect on consumer continuance behavior towards purchasing online (Bianchi and Andrews, 2012).

On the other hand, several investigations on the impact of user interface on attention, trust, and satisfaction can be found in the literature.

\section{Literature review}

For instance, Lindgaard et al. (2011) believe a well-designed web site gains more attention, trust, and satisfaction. Besides, Fruhling and Lee (2006), said: "UI usability factors are essential elements in conveying the trustworthiness of a web-based system and do affect consumers' perception of trust in personal relationship-based information exchanges." Moreover, Wang and Emurian (2005), suggest that the visual design of an e-commerce interface may have a great impression on online shoppers' trust. 
For this reason, Pengnate and Sarathy (2017), examined the relationship between web site design and user trust. The results of their analysis indicate the visual appeal of a web site gains more trust than the ease of use. Regardingly, Fogg et al. (2003), asked 2,684 people to evaluate the credibility of two web sites in the same field. The participants were asked to write their reasons for each website. Eventually, it turned out the design look of the web site was mentioned $46.1 \%$ than other reasons. The next most common answer was about information structure (28.5\%). Robins and Holmes (2008), also explained the amelioration effect of a web page aesthetics on credibility. They showed 42 web pages to 20 participants and asked them to rank each site's credibility, and found that the sites with a higher aesthetic quality, have a higher credibility rank.

On the other hand, Tseng and Tseng (2014), did two experiments with online payment scenarios. In the first one, twenty participants were asked to choose between five online shopping web pages with different amounts of text information to finish a simulated shopping and then evaluate their credibility. The result showed that there is a direct relationship between text-based complexity and users' trust. The second experiment repeated with the same participants and the five shopping web pages modified by adjusting the picture components. A reverse relationship between image-based complexity and users' credibility was concluded.

Besides all the previous work that has been done, the effect of payment gateway page UI design on customers' final payments is still indeterminate, but today, trying to Understand consumer behavior is essential to consumer-oriented e-business models (Verhagen et al., 2006). The user interface covered information on which users' decisions and the interpretation of their actions depend (Yee, 2002). Today, the needs for effective interface design have been increased to make the kind of contribution to human understanding (Blair-Early and Zender, 2008). The user unconsciously affected by what sees; hence, the relationships with products were shaped by arousing emotions visually, and the user interface could encourage either secure or insecure behavior (Chiasson et al., 2009). User trust affected strongly by privacy and security concerns, information quality of the website, and the company's reputation (Kim et al., 2008).

\section{Conceptual framework}

Based on theories in the human-computer interaction and Information Systems domains, we shaped our conceptual framework.

Our theoretical research developed to test the impact of user interface on trust impression. As Pengnate and Sarathy (2017) and Cyr et al. (2006) studied, The users' evaluations of the online process such as trust could be affected by the visual appeal of the user interface.

\section{Hypothesis - with the same $U X$, trust in the online process could be affected by the user interface.}

For further evaluation, we examined the impact of different UI design as variables to evidence that a payment gateway plays a crucial role in customer attention, trust and prevent them from abandoning the payment form.

\section{Method}

The experiment was completed in three parts. First, the Kipo payment gateway evaluated in the marketing campaign; second, the user interface with the best visual trust impression was selected based on user rating. Finally, the Kipo payment gateway was redesigned with the new interface and re-evaluated.

To start the process, user behavior towards the Kipo payment gateway (Figure 1) was estimated in a marketing campaign conducted by "Quiz of Kings," Iran's most prominent online quiz game application with over 15 million users. KPG (Kipo Gateway Payment) is a product of Bahar Ecommerce for online payment that can be implemented on other companies' web pages or online payment applications, which was used in this study in Quiz of Kings application. We used google analytics tools to collect, organize, examine, and report customers' behavior and action. 


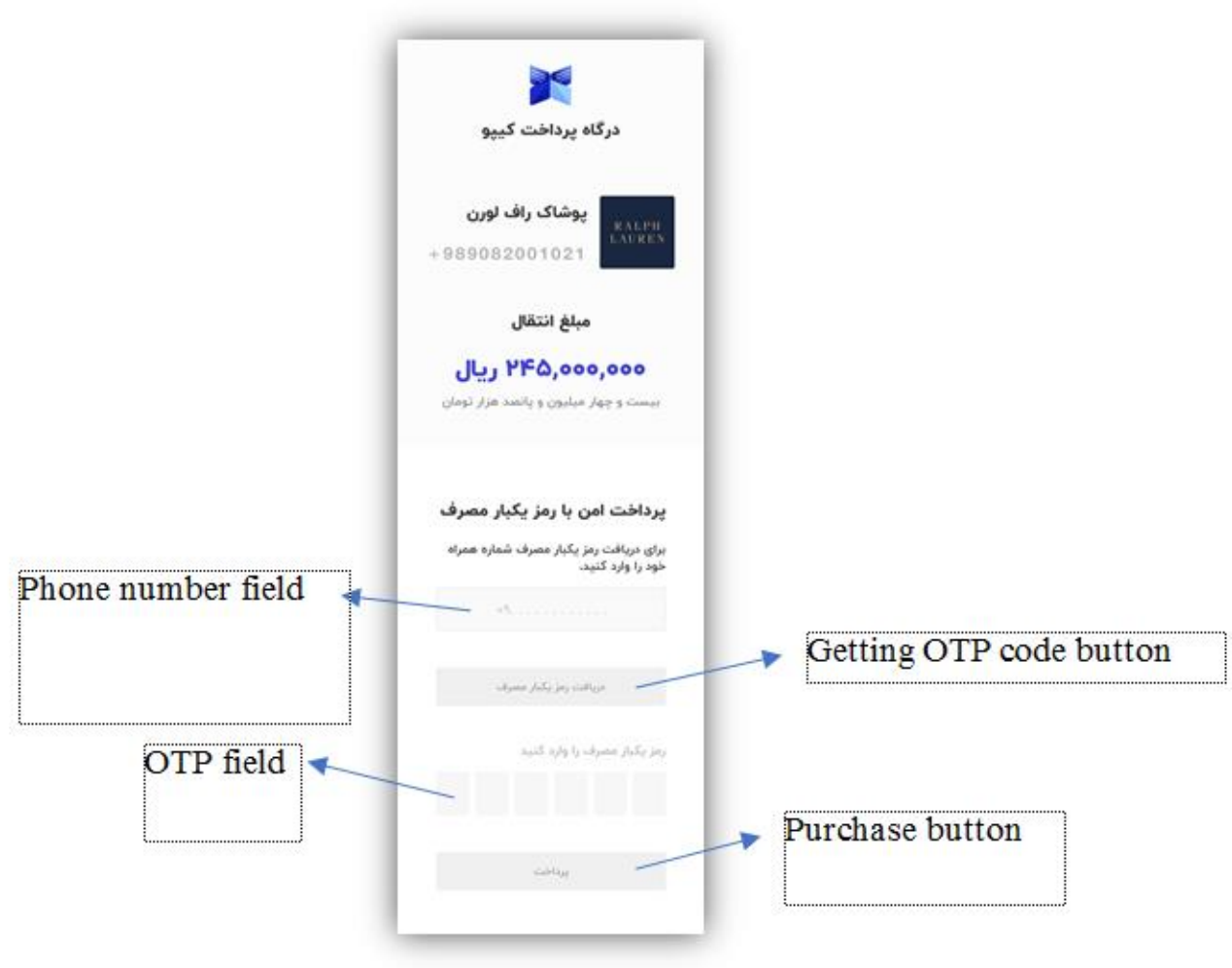

Figure 1. Kipo payment gateway

On this page, users must enter their phone number. User authentication is done using a "one-time password (OTP)" in which a verification SMS containing a 6-digit code is sent to the users' phone numbers. To complete the purchase, participants had to enter the code on the gate page.

a $\log$ analyzer, and a tool that generates advanced web, streaming, FTP, or mail server statistics, graphically.

6495 gamers participated in this experiment, which was conducted for five days. The participant were players of the Quiz of kings' game who had never bought any coins in that game before. The biggest demographic group were males $(54.15 \%)$ between $25-34$ years old, while $76.5 \%$ of all users were aged between 18 and 44 (Figure 2)

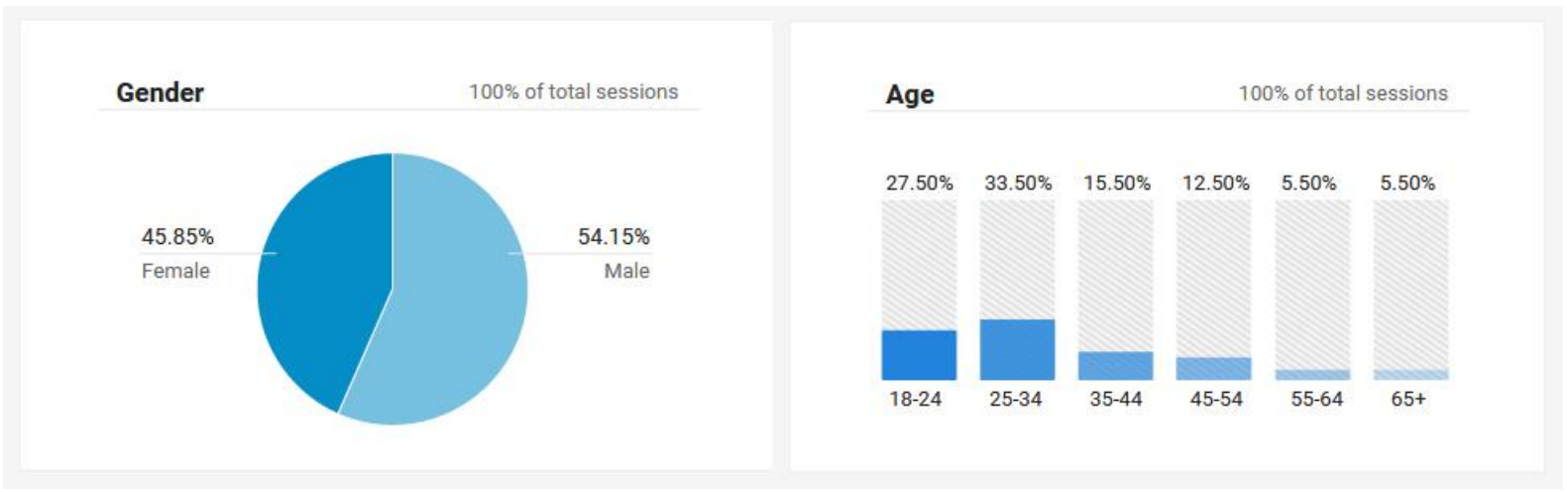

Figure 2. Age and gender of participants

The marketing plan proposed $10 \%$ discount for buying the game's coins (The coins are used to unlock the game's levels). The proposal was shown to the participants as a banner ad. By touching the banner, users have been directed to the campaign page to buy Quiz coins. To complete their payment, they were going to Kipo payment gateway in which the total amount of their purchase was shown. In this part of the experiment, statistics of new users and actions like entering phone numbers and receiving OTP code have been documented. (Figure 3). 


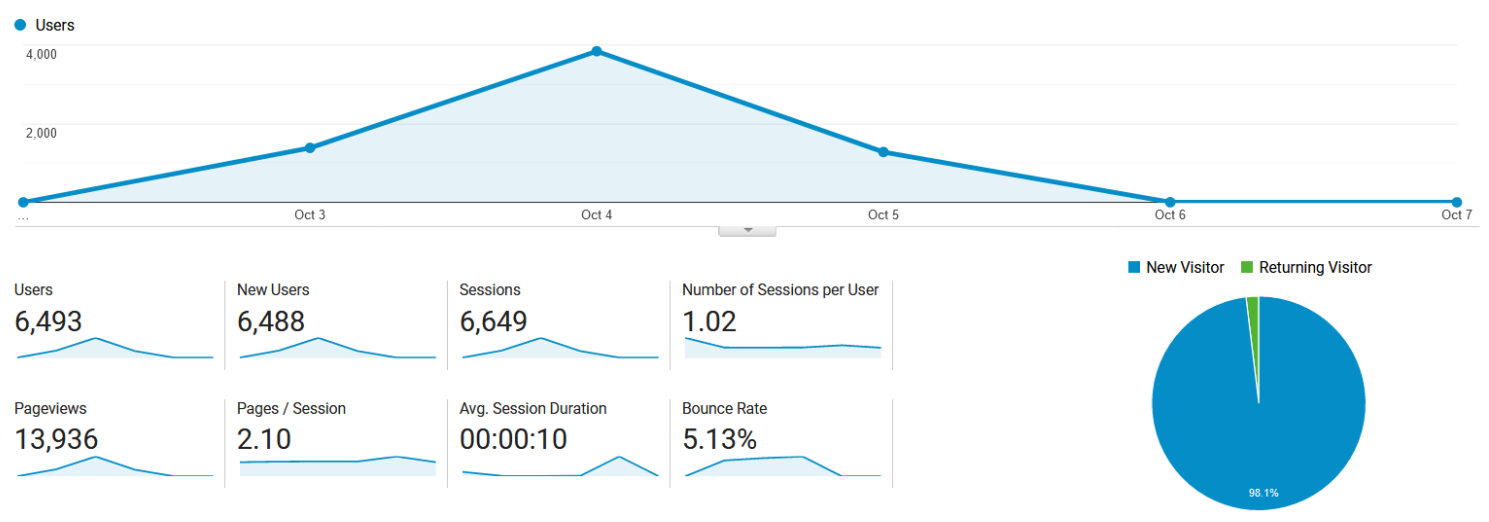

Figure 3. Result of the first marketing campaign

To measure user trust, a survey was designed. Eight most-used Iranian gateways were selected, and the interface of the Kipo payment gateway was redesigned based on their colors, layout, structure, and icons. In other words, with the same user experience, new eight user interfaces were designed for the Kipo payment gateway page. Next, another group of participants was asked to rate the credibility of each UI according to their sense of trust.

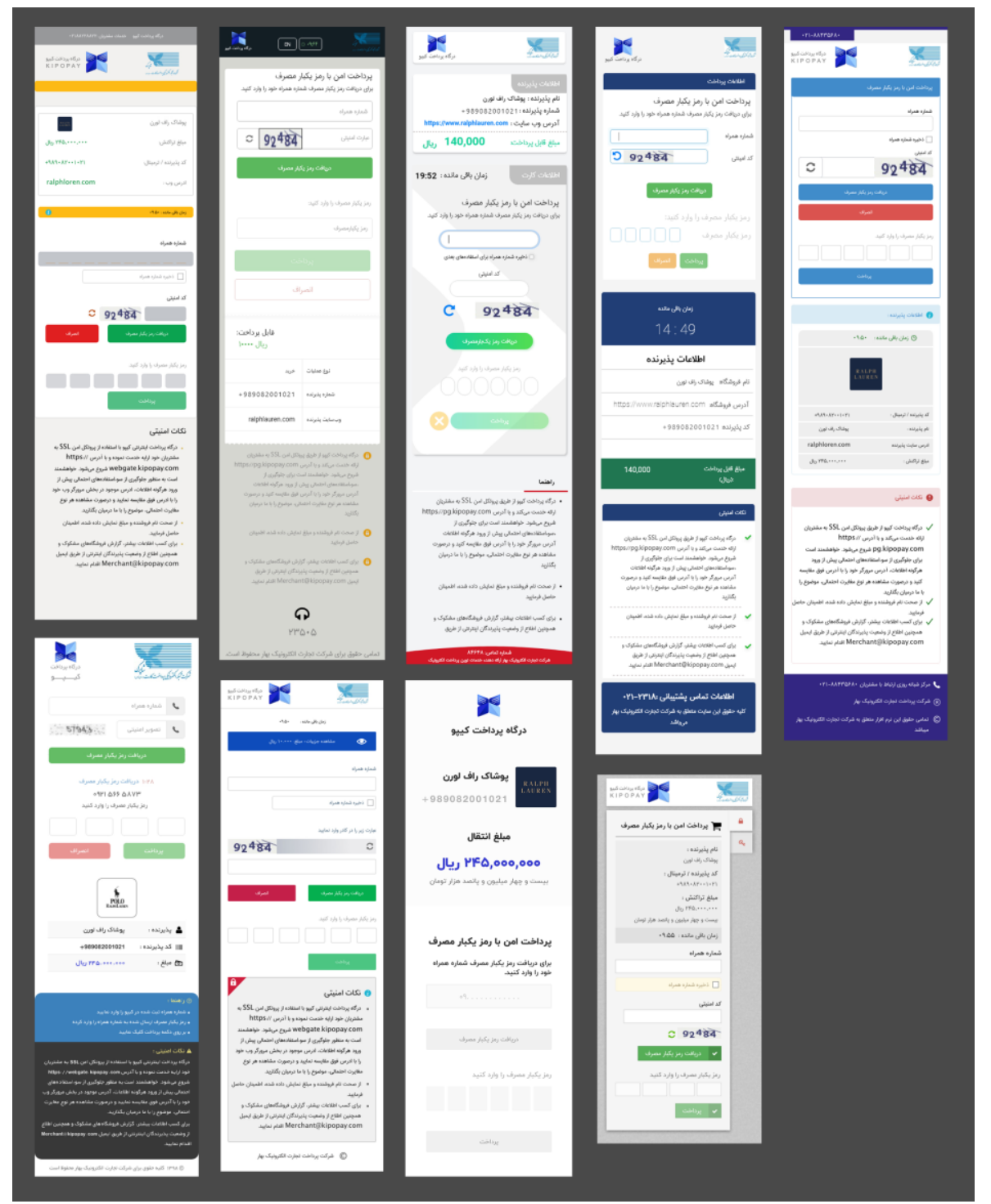

Figure 4. New interfaces based on Kipo payment gateway's UX and famous gateways' UI 
Before conducting the survey, two experts, a psychologist, and a designer, have reviewed the questions. Also, a pilot study with six people carried out in advance to ensure the accuracy of the survey. 160 participants who were selected voluntarily by the convenient sampling method completed the survey. They were 18 to 66 years old, with an average age of $27.49 .7 \%$ of them were male, $47.8 \%$ female and $2.5 \%$ did not share their gender. Most of them were educated; $42.2 \%$ had bachelor, and 34.8\% had master's degrees. The purpose of this distinguishing semantic questionnaire was to measure users' trust just based on the user interface. For this purpose, significant factors changed in each user interface prototype including color, layout, font, composition, and design spirit. The survey was distributed online by "Google Form." It had two parts; personal information and UI designs. Users should score from 1 (no confidence) to 5 (complete confidence) based on their visual trust impression in each of the payment gateways. Kipo payment gateway average score was 2.45, but the winner gateway (Saman) score was 3.75 (Figure 5).

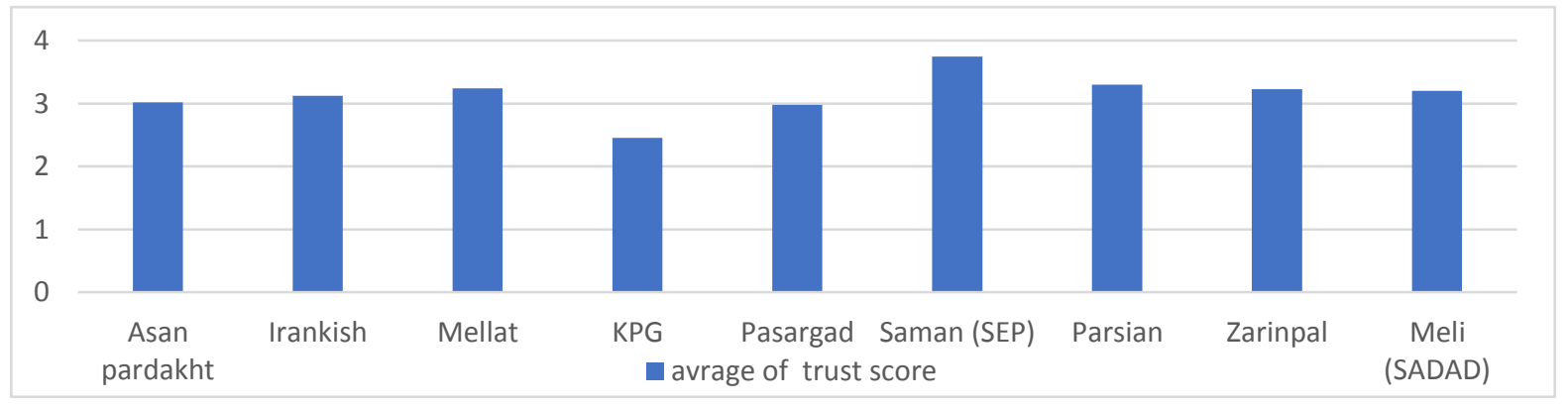

Figure 5. Trust score of payment gateways by participants

Based on the questionnaire's results, the Kipo payment gateway was redesigned (Figure 6) and relaunched in the Quiz of King marketing campaign with the same method and the same user profile in four days.

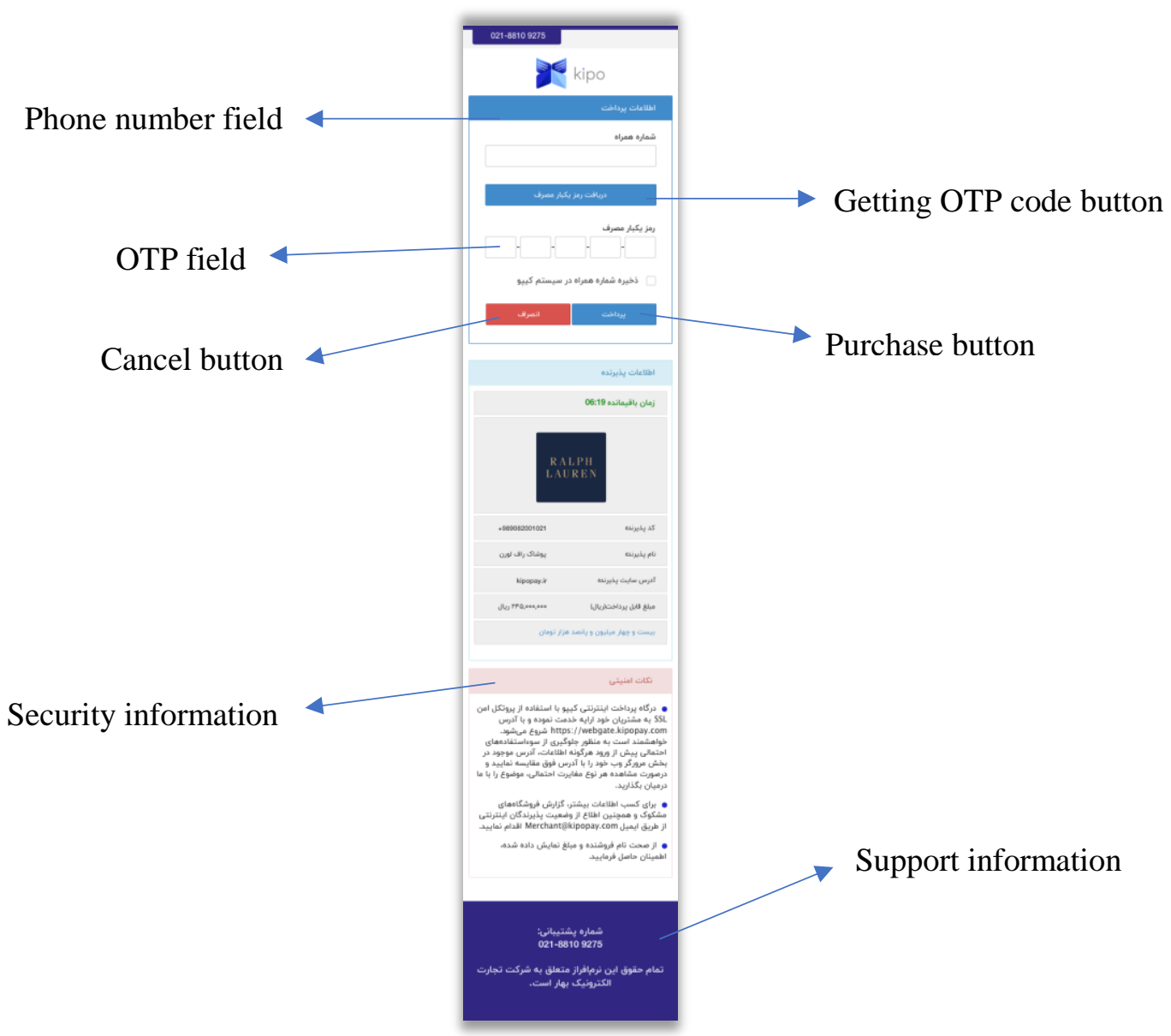

Figure 6. The new user interface of Kipo payment gateway 
The results were recorded to gauge the impact of the changes on users. 3703 users from seventh to the 10th of Nov 2019 participated in the marketing campaign (Figure 7).

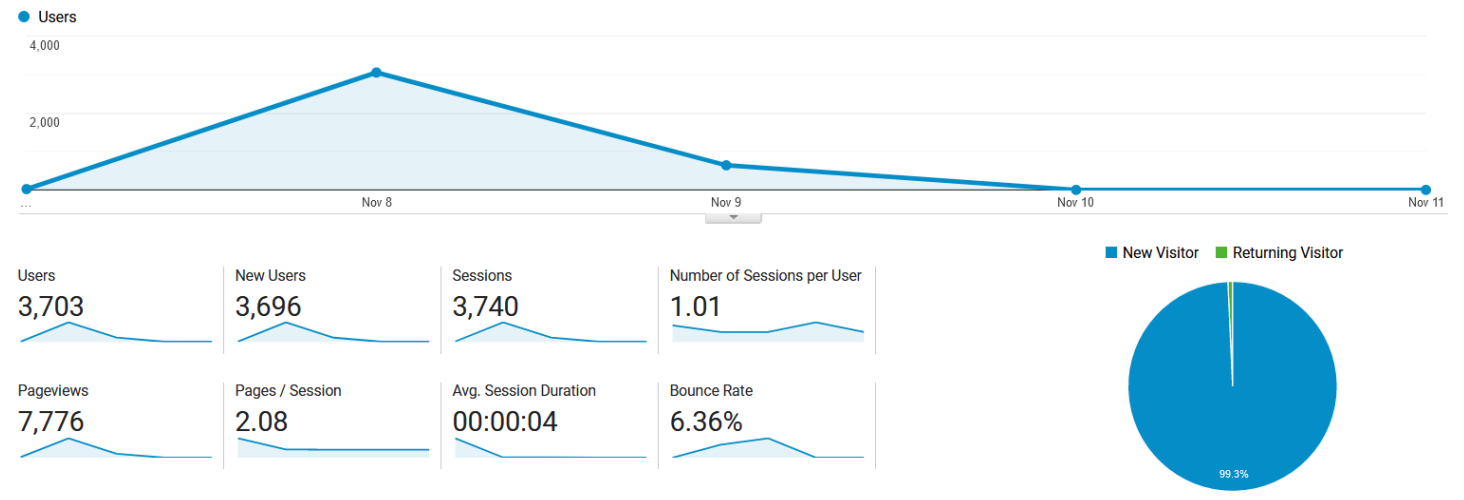

Figure 7. Result of the second marketing campaign

The statistics of new users and actions like entering phone numbers and receiving OTP code were documented, and the results were compared to each other.

\section{Results}

Friday was chosen because of similarities in the number of entries and the research conditions in both campaigns. In the first marketing campaign with Quiz of Kings, 3831 new users (Figure 8), and the second one, 3045 users (Figure 9) participated. Sessions and page views in the first camping were more than the second one, but the bounce rate was decreased by $1.27 \%$ in the second campaign. There were similarities between users' behavior in both campaigns in hours and volume of use. The lowest number of users was at $5 \mathrm{am}$, and the maximum was $2 \mathrm{pm}$.

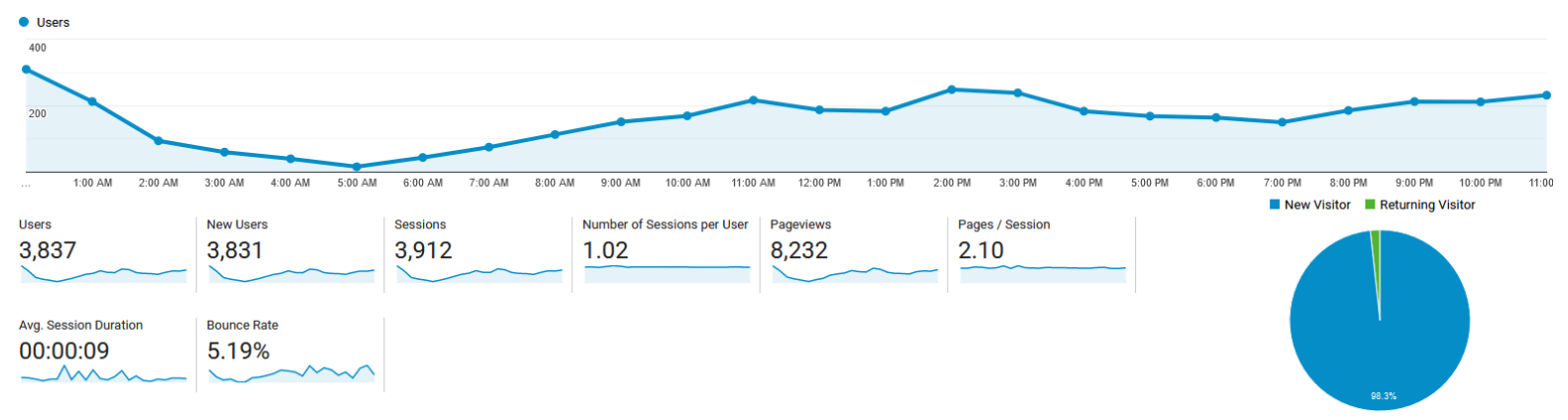

Figure 8. First Friday in the campaign (4th of Oct)

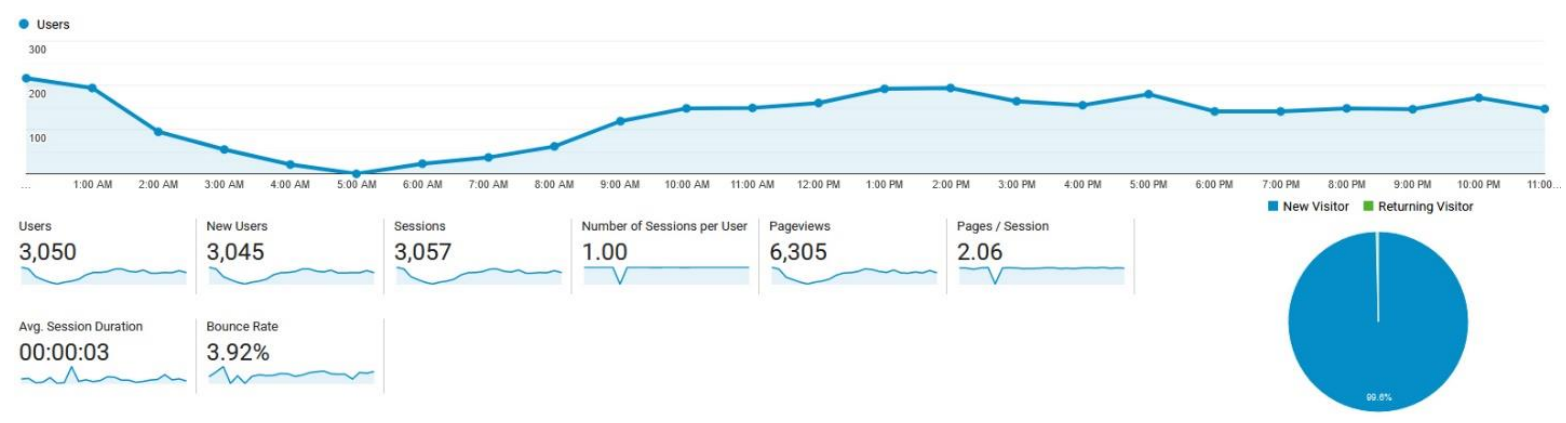

Figure 9. Second Friday in the campaign (8th of Nov)

In the two mentioned campaigns, all conditions were the same except the user interface. Logs and data on server-side visualize by AM charts (Figure 10). Results showed that users entering the phone 
number in the second campaign among all users who viewed the page increased from $23.4 \%$ to $54.5 \%$, and user OTP improved 5\% (from $1 \%$ to $6 \%$ ).

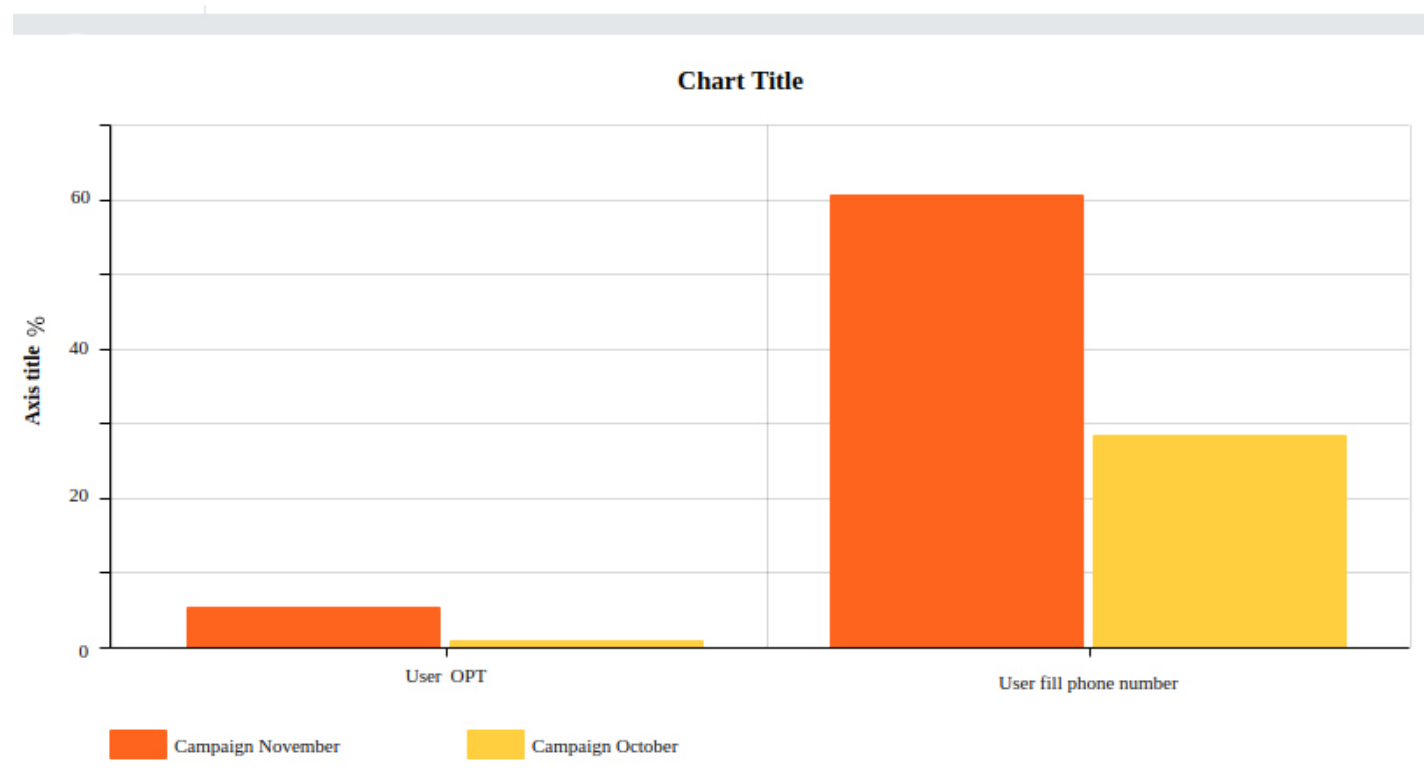

Figure 10. Data of server and logs

\section{Discussion and conclusion}

In this research, "trust" as an essential factor in e-commerce and "user interface" as the primary visual connector between users and products, have been reviewed. This case study on payment gateways follows the effect of changing the user interface on user trust. For finding the correlation between the visual aspect of a Payment Gateways and shoppers' trust, we had three user-centered interface evaluation steps to find an optimal way to make a better payment gateway.

The first step results showed that the main challenge is convincing users to enter their phone numbers. The fear of encountering phishing sites makes users reluctant to enter their phone numbers anywhere (El-Din et al., 2014). So, we tried to find UI patterns that helped users to trust the gateways in their purchase process. Hence, a survey for measuring the success of other payment gateways in gaining customer confidence enabled us to design a new interface based on them. However, new UI remind secure gateways for users because it got inspire from familiar pages for them.

The user experience was similar to the previous version, but the face of the product had changed entirely. Also, the addition of security information and ways of contacting support were contributing factors to greater trust.

At the final step, we tried to make the same condition as the first examination (marketing campaign). The number of users and page entries were similar. The results show that the users who declared their contact information among whole viewers increased by $31.3 \%$ due to a new UI design. This result demonstrates the improvement of the product and builds trust among users only through apparent changes in the product and indicate better communication and more credibility. It represents that the UI can give the users a sense of security when it is designed based on everyday items that they have seen before. As we know, based on MAYA principle, when users agree on originality and typicality, always prefer the same product (Hekkert, 2006) and using familiar faces in UI design helps them to make a better connection with new interfaces. Trendiness, complexity, and emotion are three dimensions of novelty (Hung and Chen, 2012) and a combination of familiar interface with the novelty of a new payment method can be desirable for the user.

\section{Acknowledgment}

This research was supported by our company, Bahar E-Commerce Services, and we thank our colleagues, who provided insight and expertise that greatly assisted the research. 


\section{References}

Bianchi, C. and Andrews, L. (2012), "Risk, trust, and consumer online purchasing behaviour: a Chilean perspective", International Marketing Review, Vol. 29 No. 3, pp. 253-275. https://doi.org/10.1108/ 02651331211229750

Blair-Early, A. and Zender, M. (2008), “User Interface Design Principles for Interaction Design”, Design Issues, Vol. 24 No. 3, pp. 85-107. https://doi.org/10.1162/desi.2008.24.3.85

Chiasson, S. et al. (2009), "User interface design affects security: patterns in click-based graphical passwords", International Journal of Information Security, Vol. 8 No. 6, pp. 387-398. https://doi.org/10.1007/s10207009-0080-7

Corbitt, B., Thanasankit, T. and Yi, H. (2003), "Trust and E-Commerce: A Study of Consumer Perceptions", Electronic Commerce Research and Applications, Vol. 2, pp. 203-215. https://doi.org/10.1016/S15674223(03)00024-3

Cyr, D., Head, M. and Ivanov, A. (2006), "Design aesthetics leading to m-loyalty in mobile commerce", Information \& Management, Vol. 43 No. 8, pp. 950-963. https://doi.org/10.1016/j.im.2006.08.009

El-Din, R.S., Cairns, P. and Clark, J. (2014), "Mobile Users Strategies for Managing Phishing Attacks", Journal of Management and Strategy, Vol. 5 No. 2. https://doi.org/10.5430/jms.v5n2p70

Fogg, B.J. et al. (2003), "How do users evaluate the credibility of Web sites?", Proceedings of the 2003 Conference on Designing for User Experiences - DUX 03. https://doi.org/10.1145/997078.997097

Fruhling, A.L. and Lee, S.M. (2006), "The influence of user interface usability on rural consumers trust of ehealth services", International Journal of Electronic Healthcare, Vol. 2 No. 4, p. 305. https://doi.org/ 10.1504/ijeh.2006.010424

Hekkert, P. (2006), "Design aesthetics: principles of pleasure in design", Psychology Science, Vol. 48 No. 2 , pp. $157-172$

Hung, W.-K. and Chen, L.-L. (2012), "Effects of Novelty and Its Dimensions on Aesthetic Preference in Product Design", International Journal of Design, Vol. 6 No. 2, pp. 81-90. http://128.199.168.50/index.php/ IJDesign/article/view/1146

Kim, D.J., Ferrin, D.L. and Rao, H.R. (2008), "A trust-based consumer decision-making model in electronic commerce: The role of trust, perceived risk, and their antecedents”, Decision Support Systems, Vol. 44 No. 2, pp. 544-564. https://doi.org/10.1016/j.dss.2007.07.001

Lindgaard, G. et al. (2011), "An exploration of relations between visual appeal, trustworthiness and perceived usability of homepages", ACM Transactions on Computer-Human Interaction, Vol. 18 No. 1, pp. 1-30. https://doi.org/10.1145/1959022.1959023

Pengnate, S.F. and Sarathy, R. (2017), "An experimental investigation of the influence of website emotional design features on trust in unfamiliar online vendors", Computers in Human Behavior, Vol. 67, pp. 49-60. https://doi.org/10.1016/j.chb.2016.10.018

Robins, D. and Holmes, J. (2008), “Aesthetics and credibility in web site design”, Information Processing \& Management, Vol. 44 No. 1, pp. 386-399. https://doi.org/10.1016/j.ipm.2007.02.003

Tseng, K.-T. and Tseng, Y.-C. (2014), "The Correlation between Visual Complexity and User Trust in On-line Shopping: Implications for Design", Human-Computer Interaction. Applications and Services Lecture Notes in Computer Science, pp. 90-99. https://doi.org/10.1007/978-3-319-07227-2_10

Verhagen, T., Meents, S. and Tan, Y.-H. (2006), "Perceived risk and trust associated with purchasing at electronic marketplaces", European Journal of Information Systems, Vol. 15 No. 6, pp. 542-555. https://doi.org/10.1057/palgrave.ejis.3000644

Wang, Y.D. and Emurian, H.H. (2005), "Trust in E-Commerce", Journal of Electronic Commerce in Organizations, Vol. 3 No. 4, pp. 42-60. https://doi.org/10.4018/jeco.2005100103

Yee, K.-P. (2002), "User Interaction Design for Secure Systems", Information and Communications Security Lecture Notes in Computer Science, pp. 278-90. https://doi.org/10.1007/3-540-36159-6_24 